\title{
Prevalence of antibodies against influenza A and B viruses in children in Germany, 2008 to 2010
}

\author{
A Sauerbrei (Andreas.Sauerbrei@med.uni-jena.de) ${ }^{1}$, T Langenhan ${ }^{1}$, A Brandstädt ${ }^{2}$, R Schmidt-Ott ${ }^{3}$, A Krumbholz ${ }^{4}$, H Girschick 5 , \\ H Huppertz ${ }^{6}$, P Kaiser ${ }^{6}$, J Liese ${ }^{7}$, A Streng ${ }^{7}$, T Niehues ${ }^{8}$, J Peters ${ }^{9}$, A Sauerbrey ${ }^{10}$, H Schroten ${ }^{11}$, T Tenenbaum ${ }^{11}$, S Wirth ${ }^{12}$, P Wutzler ${ }^{1}$ \\ 1. Institute of Virology and Antiviral Therapy, Jena University Clinic, Friedrich Schiller University of Jena, Jena, Germany \\ 2. Institute of Medical Statistics, Computer Sciences and Documentation, Jena University Clinic, Jena, Germany \\ 3. GlaxoSmithKline, Munich, Germany \\ 4. Institute for Infection Medicine, Christian Albrecht University of Kiel, Kiel, Germany \\ 5. Clinic of Paediatrics and Adolescent Medicine, Vivantes Clinic in Friedrichshain, Berlin, Germany \\ 6. Children's Hospital, Bremen, Germany \\ 7. University Children's Hospital, Paediatric Infectious Diseases, Wuerzburg, Germany \\ 8. HELIOS Children's Hospital, Krefeld, Germany \\ 9. Department of Paediatrics and Adolescent Medicine, Clinic Dritter Orden, Munich, Germany \\ 10. HELIOS Children's Hospital, Erfurt, Germany \\ 11. University Children's Hospital Mannheim, Heidelberg University, Germany \\ 12. HELIOS Children`s Hospital, Witten/Herdecke University, Wuppertal, Germ
}

Citation style for this article:

Sauerbrei A, Langenhan T, Brandstädt A, Schmidt-Ott R, Krumbholz A, Girschick H, Huppertz H, Kaiser P, Liese J, Streng A, Niehues T, Peters J, Sauerbrey A, Schroten H, Tenenbaum T, Wirth S, Wutzler P. Prevalence of antibodies against influenza A and B viruses in children in Germany, 2008 to 2010 . Euro Surveill. 2014;19(5):pii=20687. Available online: $h$ ttp://www.eurosurveillance.org/ViewArticle. aspx?Articleld =20687

The prevalence of influenza $A$ and $B$ virus-specific IgG was determined in sera taken between 2008 and 2010 from 1,665 children aged $0-17$ years and 400 blood donors in Germany. ELISA on the basis of whole virus antigens was applied. Nearly all children aged nine years and older had antibodies against influenza $A$. In contrast, $40 \%$ of children aged $0-4$ years did not have any influenza A virus-specific IgG antibodies. Eightysix percent of $0-6$ year-olds, $47 \%$ of $7-12$ year-olds and $20 \%$ of $13-17$ year-olds were serologically naïve to influenza B viruses. By the age of 18 years, influenza B seroprevalence reached approximately $90 \%$. There were obvious regional differences in the seroprevalence of influenza B in Germany. In conclusion, seroprevalences of influenza $A$ and influenza $B$ increase gradually during childhood. The majority of children older than eight years have basal immunity to influenza $A$, while comparable immunity against influenza $B$ is only acquired at the age of 18 years. Children aged 0-6 years, showing an overall seroprevalence of $67 \%$ for influenza $A$ and of $14 \%$ for influenza $B$, are especially at risk for primary infections during influenza $B$ seasons.

\section{Introduction}

Influenza is a major public health threats worldwide with approximately 1 billion of the total population infected annually, resulting in 5 million serious diseases and 500,000 deaths [1]. Children are one of the most vulnerable groups since they are often immunologically naïve when placentally transferred antibodies have disappeared after ca one year of life [2], and the contacts made by children favour infections by the respiratory route [3]. Thus, influenza has been shown to be an important cause of morbidity during childhood, with attack rates ranging from $20 \%$ to $30 \%$ during epidemics [4]. Furthermore, infants and children with underlying disease are at increased risk of severe influenza and influenza-associated mortality [5-7]. Several studies have shown that influenza in childhood has considerable socioeconomic impact on the children's households $[4,8,9]$ because children are regarded as the main and most efficient transmitters for spreading influenza in the community.

The most effective existing intervention to prevent morbidity and mortality of children due to influenza is the annual vaccination against seasonal influenza [10]. A study in Germany has shown that $50 \%$ of severe influenza cases in paediatric intensive care units might have been prevented if the current recommendations for vaccination, which only include risk groups of children, had been followed [6]. As demonstrated in several randomised clinical trials, intranasal live attenuated influenza vaccine has higher efficacy than the standard inactivated split vaccine and may improve vaccination in children $[11,12]$. However, owing to variations in circulating virus strains and in children's immune systems, current influenza vaccines are not fully protective [13]. Immunologically naïve younger children may be at increased risk of severe influenza disease and will therefore benefit from vaccination more than older children who have already had one or more influenza virus infections. This may explain why hospitalisation rates related to influenza virus infections are high in young children and comparable to those observed in adults over 60 years [14-16]. Therefore, seroepidemiological data on influenza A and B during childhood as a surrogate for type-specific priming are a fundamental prerequisite for the development of efficacious 
Prevalence of IgG antibodies against influenza A virus in children (aged 0-17 years, n=1,664 ${ }^{\mathrm{a}}$ ) and adults (blood donors aged 18-65 years, $\mathrm{n}=400)$, Germany, 2008-11

\begin{tabular}{|c|c|c|c|c|c|c|}
\hline \multirow[b]{2}{*}{$\begin{array}{l}\text { Age group } \\
\text { in years }\end{array}$} & \multicolumn{2}{|c|}{ Male } & \multicolumn{2}{|c|}{ Female } & \multicolumn{2}{|c|}{ Male and female } \\
\hline & $\begin{array}{c}\text { Number of positive } \\
\text { samples/total } \\
\text { number }\end{array}$ & $\begin{array}{l}\text { Percentage ( } 95 \% \\
\text { Cl) }\end{array}$ & $\begin{array}{c}\text { Number of positive } \\
\text { samples/total } \\
\text { number }\end{array}$ & $\begin{array}{l}\text { Percentage }(95 \% \\
\mathrm{Cl})\end{array}$ & $\begin{array}{c}\text { Number of positive } \\
\text { samples/total } \\
\text { number }\end{array}$ & $\begin{array}{l}\text { Percentage ( } 95 \% \\
\text { Cl) }\end{array}$ \\
\hline \multicolumn{7}{|c|}{ Infants, children and adolescents } \\
\hline $0-2$ & $71 / 150$ & $47.3(39.1-55.6)$ & $55 / 121$ & $45.4(36.4-54.8)$ & $126 / 271$ & $46.5(40.4-52.6)$ \\
\hline $3-4$ & $81 / 104$ & $77.9(68.7-85.4)$ & $59 / 71$ & $83.1(72.3-91.0)$ & $140 / 175$ & $80.0(73.3-85.7)$ \\
\hline $5-6$ & $64 / 74$ & $86.5(76.6-93.3)$ & $71 / 77$ & $92.2(83.8-97.1)$ & $135 / 151$ & $89.4(83.4-93.8)$ \\
\hline $7-8$ & $86 / 89$ & $96.6(90.5-99.3)$ & $82 / 86$ & $95.3(88.5-98.7)$ & $168 / 175$ & $96.0(91.9-98.4)$ \\
\hline $9-10$ & $95 / 97$ & $97.9(92.8-99.8)$ & $95 / 95$ & $100.0(96.2-100.0)$ & $190 / 192$ & $99.0(96.3-99.9)$ \\
\hline $11-12$ & $100 / 100$ & $100.0(96.4-100.0)$ & $101 / 101$ & $100.0(96.4-100.0)$ & $201 / 201$ & $100.0(98.2-100.0)$ \\
\hline $13-14$ & $112 / 112$ & $100.0(96.8-100.0)$ & $111 / 112$ & $99.1(95.1-100.0)$ & $223 / 224$ & $99.6(97.5-100.0)$ \\
\hline $15-17$ & $113 / 113$ & $100.0(96.8-100.0)$ & $162 / 162$ & $100.0(97.8-100.0)$ & $275 / 275$ & $100.0(98.7-100.0)$ \\
\hline Total & $722 / 839$ & $86.1(83.5-88.3)$ & $736 / 825$ & $89.2(86.9-91.2)$ & $1,458 / 1,664$ & $87.6(85.9-89.2)$ \\
\hline \multicolumn{7}{|c|}{ Adults (blood donors) } \\
\hline $18-29$ & $78 / 79$ & $98.7(93.3-100.0)$ & $72 / 72$ & $100.0(95.0-100.0)$ & $150 / 151$ & $99.3(96.4-100.0)$ \\
\hline $30-45$ & $67 / 72$ & $93.1(84.5-97.7)$ & $52 / 52$ & $100.0(93.2-100.0)$ & $119 / 124$ & $96.0(90.8-98.7)$ \\
\hline $46-65$ & $71 / 78$ & $91.0(82.4-96.3)$ & $45 / 47$ & $95.7(85.5-99.5)$ & $116 / 125$ & $92.8(86.8-96.7)$ \\
\hline Total & $216 / 229$ & $94.3(90.5-96.9)$ & $169 / 171$ & 98.8 (95.8-99.9) & $385 / 400$ & 96.3 (93.9-97.9) \\
\hline
\end{tabular}

a For one patient, there was only enough serum to perform the test against influenza B.

vaccination policies for children. To date, the available data are scarce, and restricted to regional sampling points [2] or virus strain-specific tests $[17,18]$. The seroprevalence against influenza $A$ and $B$, determined by sensitive and specific type-specific ELISA, may be a good surrogate marker for immunological priming since strain-specific assays such as the haemagglutination inhibition test depend on carefully selected panels of virus antigens and may underestimate the true seroprevalence.

Here, we describe a multicentre seroepidemiological study to determine influenza $A$ and $B$ antibody prevalence in infants, children and adolescents in Germany. Sera were obtained between 2008 and 2010 from nine paediatric and diagnostic centres throughout Germany. To compare these data with the influenza seroprevalence in adults, sera from blood donors were included. For the determination of influenza A- and B-specific IgG antibodies, type-specific ELISA with high sensitivity and specificity was used.

\section{Methods}

\section{Patients and serum samples}

A total of 1,665 sera from children aged one month to 17 years and 400 sera from blood donors aged 18 to 65 years were included. Sera of children were collected primarily between 2008 and 2010 from eight German paediatric primary care hospitals (Bremen, Berlin, Krefeld, Wuppertal, Erfurt, Würzburg, Mannheim, Munich) and one diagnostic institute (UIm) for seroprevalence studies of pandemic influenza A [19]. Children with an illness impeding an adequate immune response were excluded. Some $15.8 \%(220 / 1,396)$ of children had been vaccinated against seasonal influenza and $7.1 \%$ $(99 / 1,396)$ against pandemic influenza $A$ between 2008 and 2010, but the reasons were unknown. This means that the vaccination was carried out in the same year or one year before the sample was taken. Sera of blood donors aged 18 to 65 years were collected anonymously between 2010 and 2011 mainly in NorthRhine Westphalia (German Red Cross blood donation centre Muenster, 337/400, 84.3\%) and in Lower Saxony (German Red Cross blood donation centre Springe, $63 / 400,15.7 \%$ ) and there was no information about the donors' vaccination status against influenza. However, an average vaccination rate of $15-20 \%$ can be assumed [20].

In accordance to recommendations of the Central Ethical Committee of Germany [21], patient consent is not required for studies on anonymised residual samples. The Ethical Committee of the Jena University approved the study protocol.

\section{Testing of sera}

Sera were stored in aliquots at $-20^{\circ} \mathrm{C}$ without interruption until testing. All sera were brought to room temperature immediately before testing. Antibody testing was carried out blindly in groups of 90 serum samples. Sera were tested in parallel using influenza virus A IgG 
Regional distribution of influenza A and B seroprevalence in children (aged 0-17 years, n=1,665) of nine German paediatric or diagnostic centres, 2008-10

\begin{tabular}{|l|c|c|c|}
\hline \multirow{2}{*}{$\begin{array}{l}\text { Center } \\
\text { (Number of sera) }\end{array}$} & Mean age in years & \multicolumn{2}{|c|}{ Seroprevalence in percentage (95\% Cl) } \\
\cline { 3 - 4 } & & $90.7(87.3-93.5)$ & $49.5(44.2-54.7)$ \\
\hline Wuppertal (366) & 9.6 & $81.7(76.6-86.2)$ & $34.7(29.0-40.7)$ \\
\hline Bremen (268) & 8.3 & $81.7(76.6-86.2)$ & $51.4(45.4-57.5)$ \\
\hline Ulm (278) & 8.2 & $89.3(84.6-93.1)$ & $48.4(41.8-55.2)$ \\
\hline Mannheim (225) & 8.4 & $97.9(93.9-99.6)$ & $64.3(55.8-72.2)$ \\
\hline Würzburg (140) & 9.9 & $98.2(93.6-99.8)$ & $46.9(37.3-56.6)$ \\
\hline Krefeld (111) & 11.2 & $75.7(66.5-83.5)$ & $25.9(18.0-35.3)$ \\
\hline Erfurt (108) & 5.8 & $90.6(82.3-95.9)$ & $52.9(41.8-63.4)$ \\
\hline Berlin (85) & 8.5 & $89.3(80.6-95.0)$ & $50.0(38.9-61.1)$ \\
\hline Munich (84) & 9.1 & & \\
\hline
\end{tabular}

ELISA (IBL International, Hamburg, Germany) and influenza virus B IgG ELISA (Euroimmun, Lübeck, Germany). These two ELISAs had been selected as the most sensitive and specific tests after comparing different commercially available ELISAs for influenza A and B IgG. Testing of defined serum samples from children [2], newborns and their mothers [22] by several commercial ELISAs, including the haemagglutination inhibition assay [23], revealed sensitivities $\geq 97 \%$ and no crossreactivities between influenza $A$ and $B$ virus or to other viral pathogens for the ELISAs used in this study. Both ELISAs were carried out manually and used for qualitative and semi-quantitative antibody testing. All samples were tested twice on different days, and sera with the same qualitative results were included in this study without retesting. Samples with discordant qualitative results were retested twice, and the most frequent result, including the original test result, was accepted.

The influenza virus A IgG ELISA used whole inactivated influenza virus $A$ Sydney/5/97 $\left(\mathrm{H}_{3} \mathrm{~N}_{2}\right)$ and Bejing/262/95 $\left(\mathrm{H}_{1} \mathrm{~N}_{1}\right)$, and the influenza $B$ IgG ELISA whole inactivated influenza virus $B$ Hongkong/5/72 as antigens in pre-coated microtitration strips. The antigen solutions contained high amounts of conserved influenza type-specific nucleo- and matrix proteins. Testing of sera was carried out at the dilution of 1:100 according to the manufacturer's instructions. Results were assessed on the basis of a standard curve calculated from three to four calibrators including positive and negative controls. In the influenza A IgG ELISA, samples were considered positive if the antibody concentration was calculated as $>12 \mathrm{U} / \mathrm{mL}$, a range of 8-12 $\mathrm{U} / \mathrm{mL}$ was considered equivocal and $<8 \mathrm{U} / \mathrm{mL}$ was interpreted as negative. For the influenza B IgG ELISA, samples were considered positive if the antibody concentration was calculated as $\geq 22$ relative units (RU) per $\mathrm{mL}$, a range of $\geq 16$ to $<22 \mathrm{RU} / \mathrm{mL}$ was considered equivocal, and $<16 \mathrm{RU} / \mathrm{mL}$ was interpreted as negative.

\section{Statistical analysis}

A sample size of about 150 subjects per pre-defined age group was planned to assure that a single two-sided $95 \%$ confidence interval $(\mathrm{Cl})$ for the prevalence of influenza $A$ and $B \lg G$ antibodies would deviate at most $8 \%$ from the observed value for a prevalence range of $5 \%$ to $95 \%$. When regional differences were analysed, less precise seroprevalences obtained from single paediatric centres resulted from small sample size. Antibody prevalence was calculated using the number of seropositive cases divided by the number of all subjects tested. Assuming binominal distribution, the two-sided exact $95 \% \mathrm{Cl}$ was calculated. The Cochran-Armitage test for trend [24] was used to examine the increase of antibody prevalence by age. Age-adjusted sex differences in antibody prevalence were investigated by the Mantel-Haenszel test [25]. Logistic regression odds ratios evaluated by the Wald statistics were used to compare age-specific prevalence of the children with the prevalence of the adult group as the whole.

Age- and sex-specific antibody concentrations were described by mean and standard deviation (SD). The association of age and sex, and the concentration of antibodies were analysed using linear multiple regression. Antibody concentrations of the different age groups of children were compared with the corresponding data of the whole adult group by the Dunnett test [26]. For both analyses, antibody concentration was transformed by the common logarithm. The level of significance was 0.05 (two-sided). The SAS V 9.2 software was used for statistical analyses.

\section{Results}

\section{Prevalence and concentrations of influenza A virus IgG}

The prevalence of IgG antibodies against influenza A virus in the samples tested is shown in Table 1. The overall prevalence of antibodies against influenza $A$ virus was $87.6 \%$ (95\% Cl: 85.9-89.2) in the tested children aged $0-17$ years; among the tested blood donors, 
Age- and sex-specific prevalence of IgG antibodies against influenza A and B virus in children (aged 0-17 years) and adults (blood donors aged 18-65 years), Germany, 2008-11 ( $n=2,065)$

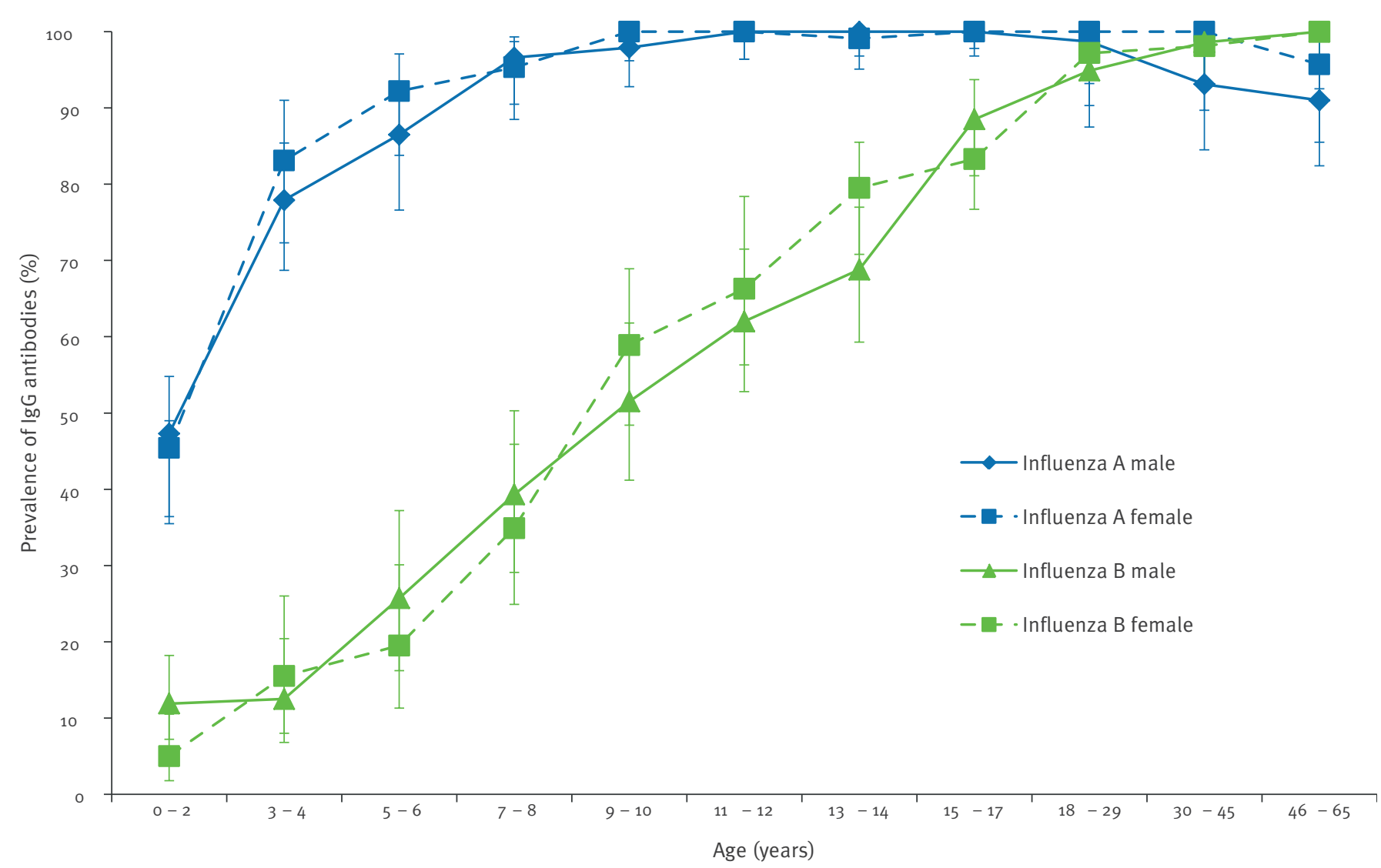

The bars show the $95 \%$ confidence intervals for the point of estimates.

the overall prevalence of influenza A IgG antibodies was $96.3 \%$ (95\% Cl: 93.9-97.9).

The regional distribution of the influenza A seroprevalence in children among the nine centres included in this study is shown in Table 2. The prevalence of antibodies ranged from $75.7 \%$ (Erfurt) to $97.9 \%$ (Würzburg); mean age of the children differed between the centres.

Figure 1 shows the age- and sex-specific prevalence of influenza A IgG in the tested children and adults (blood donors). Statistical analysis demonstrated that the antibody prevalence against influenza $A$ virus increased significantly with age in children ( $p<0.001)$ and decreased with age in adults $(p=0.004)$. Adjusted to age, there were no significant differences between the prevalence of antibodies among boys and girls $(p=0.576)$, but in blood donors a significantly higher prevalence was detected in women than in men $(p=0.031)$. Children up to the age group of five to six years had a significantly lower prevalence of antibodies than the adult controls (o-2 and 3-4 years: $p<0.001,5-6$ years: $p=0.003)$. In children vaccinated against seasonal $(p=0.002)$ or pandemic influenza $(p=0.01)$, the number of positives was significantly higher (seasonal: 209/220, 95.0\%; pandemic: $98 / 99,99.0 \%)$ than in non-vaccinated children (seasonal: 1,029/1,176, 87.5\%; pandemic: $1,140 / 1,296$, $88.0 \%)$.

In the study group of children, the mean concentration of antibodies against influenza $A$ virus was calculated as $59.95 \mathrm{U} / \mathrm{mL}$ (SD: 46.04), and the adult controls had a mean antibody concentration of $72.02 \mathrm{U} / \mathrm{mL}$ (SD: 39.90). Figure 2 shows the concentrations of antibodies against influenza $A$ virus by age and sex of the tested children and adults (blood donors). The antibody concentrations increased significantly with age during childhood ( $p<0.001$ ) and declined with age in adults $(p=0.041)$. In young adults of $18-29$ years, the mean antibody concentration was $85.75 \mathrm{U} / \mathrm{mL}$ (SD: 40.33) compared with $66.06 \mathrm{U} / \mathrm{mL}$ (SD: 38.67 ) in older adults of 46-65 years. Adjusted to age, no significant differences could be found between boys and girls $(p=0.426)$ nor between men and women $(p=0.300)$. Children up to the age group of five to six years had significantly lower concentrations of IgG antibodies against influenza $A$ virus than the control group of adults ( $p<0.001)$, whereas the antibody concentrations 
Age- and sex-specific distribution of IgG antibody concentrations against influenza A and B virus in children (aged 0-17 years) and adults (blood donors aged 18-65 years), Germany 2008-11 ( $\mathrm{n}=2,065)$

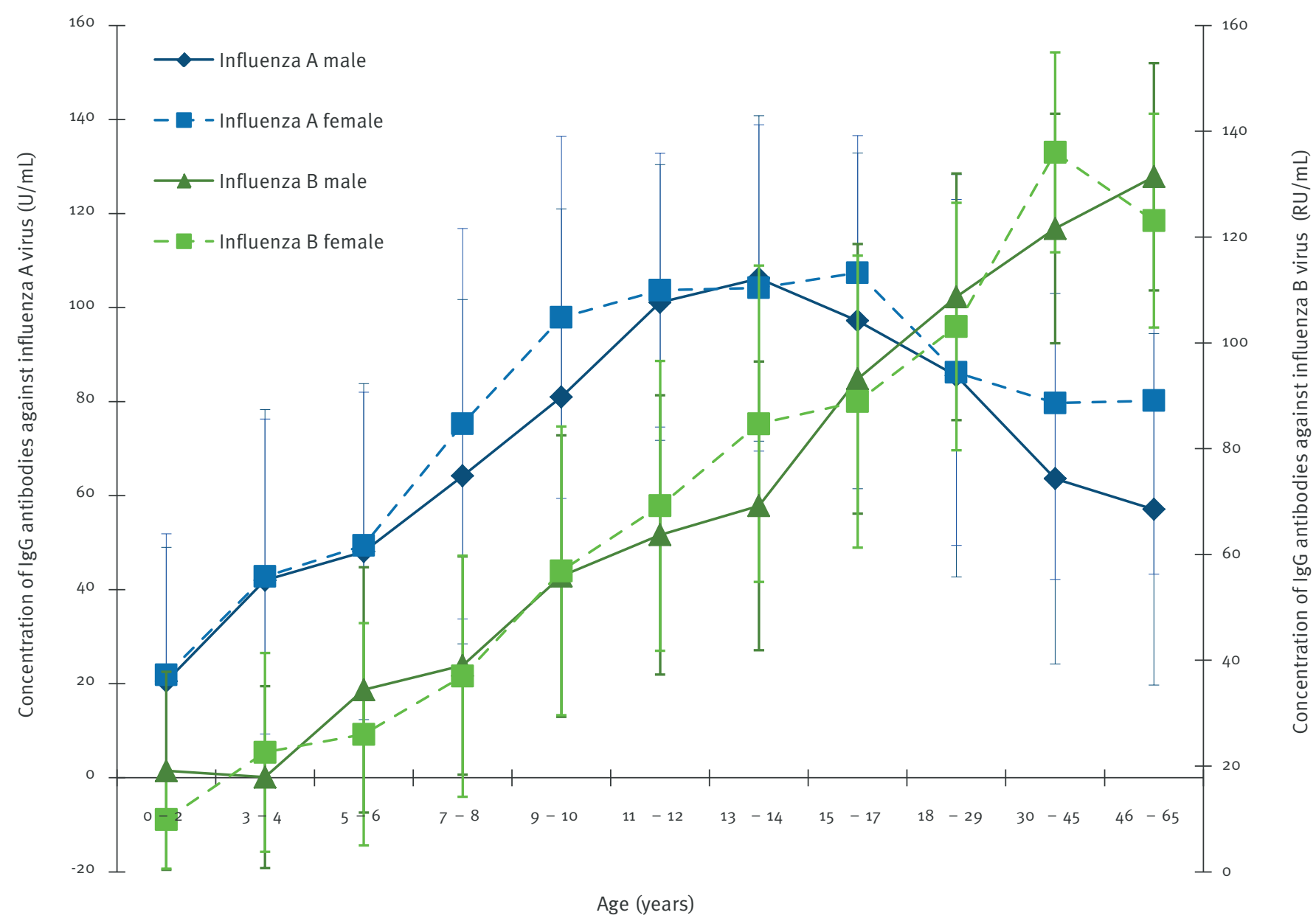

The bars show the standard deviation for the point of estimates.

were significantly higher among the 11-12 ( $p<0.001)$, 13-14 $(p=0.001)$ and 15-17 ( $p<0.001)$ year-olds than among the adults. These data were not adjusted for vaccination status.

\section{Prevalence and concentrations of influenza B virus IgG}

Table 3 shows the prevalence of antibodies against influenza $B$ virus in the samples tested. In children, the overall prevalence was $47.0 \%$ (95\% Cl: 44.6-49.5), and in the blood donors, it was $98.0 \%$ (95\% Cl: 96.1-99.1). The regional distribution of influenza $B$ seroprevalence in the nine centres is shown in Table 2 . The lowest prevalence of antibodies was found with $25.9 \%$ in the Erfurt group and the highest with $64.3 \%$ in the Würzburg group, and these prevalences were related to the mean age of the children in the different centres. The age- and sex-specific prevalences of influenza $B$ IgG in the tested children and adults (blood donors) are shown in Figure 1. Statistical analysis demonstrated that the prevalence of antibodies against influenza $B$ increased significantly with age in children ( $p<0.001)$ and adults $(p=0.018)$. Adjusted to age, there were no significant differences between the prevalence of antibodies as a function of sex for children $(p=0.977)$ and adults $(p=0.635)$. In all age groups of children, significantly lower prevalence of antibodies was measured than in the adult controls ( $p<0.001)$. In the group of children vaccinated against seasonal influenza, the number of positives (146/220, 66.4\%) was significantly higher than in the group of non-vaccinated children (497/1,176, 42.3\%, p<0.001).

The mean antibody concentrations against influenza $B$ virus were estimated as $54.67 \mathrm{RU} / \mathrm{mL}$ (SD: 55.30 ) in the study group of children and as 119.31 RU/mL (SD: 44.97) in the control group of adults (blood donors). Figure 2 shows the concentrations of influenza B-specific antibodies depending on age and sex of the tested children and adults (blood donors). The concentrations of antibodies increased with age up to the 15-17 year-olds ( $p<0.001$ ), but there were no significant differences between the three age groups of adults $(p=0.228)$. The antibody concentrations were not dependent on sex neither in the children $(p=0.317)$ nor in the adults $(p=0.892)$. For all age groups of children, significantly 
Prevalence of IgG antibodies against influenza B virus in children (aged $0-17$ years, $n=1,665$ ) and adults (blood donors aged $18-65$ years, $n=400)$, Germany, 2008-11

\begin{tabular}{|c|c|c|c|c|c|c|}
\hline \multirow[b]{2}{*}{$\begin{array}{l}\text { Age group } \\
\text { in years }\end{array}$} & \multicolumn{2}{|c|}{ Male } & \multicolumn{2}{|c|}{ Female } & \multicolumn{2}{|c|}{ Male and female } \\
\hline & $\begin{array}{c}\text { Number of positive } \\
\text { samples/total } \\
\text { number }\end{array}$ & $\begin{array}{l}\text { Percentage } \\
(95 \% \mathrm{CI})\end{array}$ & $\begin{array}{c}\text { Number of positive } \\
\text { samples/total } \\
\text { number }\end{array}$ & $\begin{array}{l}\text { Percentage } \\
(95 \% \mathrm{Cl})\end{array}$ & $\begin{array}{c}\text { Number of positive } \\
\text { samples/total } \\
\text { number }\end{array}$ & $\begin{array}{l}\text { Percentage } \\
(95 \% \mathrm{Cl})\end{array}$ \\
\hline \multicolumn{7}{|c|}{ Infants, children and adolescents } \\
\hline $0-2$ & $18 / 151$ & $11.9(7.2-18.2)$ & $6 / 121$ & $5.0(1.8-10.5)$ & $24 / 272$ & $8.8(5.7-12.8)$ \\
\hline $3-4$ & $13 / 104$ & $12.5(6.8-20.4)$ & $11 / 71$ & $15.5(8.0-26.0)$ & $24 / 175$ & $13.7(9.0-19.7)$ \\
\hline $5-6$ & $19 / 74$ & $25.7(16.2-37.2)$ & $15 / 77$ & $19.5(11.3-30.1)$ & $34 / 151$ & $22.5(16.1-30.0)$ \\
\hline $7-8$ & $35 / 89$ & $39.3(29.1-50.3)$ & $30 / 86$ & $34.9(24.9-45.9)$ & $65 / 175$ & $37.1(30.0-44.8)$ \\
\hline $9-10$ & $50 / 97$ & $51.5(41.2-61.8)$ & $56 / 95$ & $58.9(48.4-68.9)$ & $106 / 192$ & $55.2(47.9-62.4)$ \\
\hline $11-12$ & $62 / 100$ & $62.0(51.8-71.5)$ & $67 / 101$ & $66.3(56.3-75.4)$ & $129 / 201$ & $64.2(57.1-70.8)$ \\
\hline $13-14$ & $77 / 112$ & $68.8(59.3-77.2)$ & $89 / 112$ & $79.5(70.8-86.5)$ & $166 / 224$ & $74.1(67.9-79.7)$ \\
\hline $15-17$ & $100 / 113$ & $88.5(81.1-93.7)$ & $135 / 162$ & $83.3(76.7-88.7)$ & $235 / 275$ & $85.5(80.7-89.4)$ \\
\hline Total & $374 / 840$ & $44.5(41.1-48.0)$ & $409 / 825$ & $49.6(46.1-53.0)$ & $783 / 1,665$ & $47.0(44.6-49.5)$ \\
\hline \multicolumn{7}{|c|}{ Adults (blood donors) } \\
\hline $18-29$ & $75 / 79$ & $94.9(87.5-98.6)$ & $70 / 72$ & $97.2(90.3-99.7])$ & $145 / 151$ & $96.0(91.6-98.5)$ \\
\hline $30-45$ & $71 / 72$ & $98.6(92.5-100.0)$ & $51 / 52$ & $98.1(89.7-100.0)$ & $122 / 124$ & $98.4(94.3-99.8)$ \\
\hline $46-65$ & $78 / 78$ & $100.0(95.4-100.0)$ & $47 / 47$ & $100.0(92.5-100.0)$ & $125 / 125$ & $100.0(97.1-100.0)$ \\
\hline Total & $224 / 229$ & $97.8(95.0-99.3)$ & $168 / 171$ & $98.2(95.0-99.6)$ & $392 / 400$ & $98.0(96.1-99.1)$ \\
\hline
\end{tabular}

lower antibody concentrations were measured compared with the control group of adults (p<0.001).

\section{Discussion}

In this study, it was of particular interest to determine influenza seroprevalence of children up to the age of 17 years in Germany. To obtain data most widely representative for the whole population of children in Germany, nine different German regions were included. A recently published study on the influenza seroprevalence in Germany included only sera from children who lived in the German federal state Thuringia [2], and the results were not regarded as representative for the entire country. Furthermore, as that study used other serological methods than ours, the results are only comparable to a limited extent.

To date, the haemagglutination inhibition test or microneutralisation assays are the gold standards to determine IgG antibodies to influenza viruses in seroprevalence studies, and the only current correlate of immunity to influenza $A$ and $B$ is based on haemagglutination inhibition titre $[17,18,27]$. However, these assays are even virus strain- or lineage- and subtypespecific, and studies carried out with a limited or poorly chosen panel of viral antigens may underestimate the true seroprevalence [28]. Furthermore, these assays are not suitable for large-scale studies because they are labour-intensive, time-consuming, not amenable to automation and not commercially available. Thus, sensitive and specific ELISAs mainly targeting conserved type-specific antibodies against the influenza virus nucleo- and matrix proteins have been used successfully in several studies for the determination of influenza seroprevalence in humans as well as pigs $[2,22,28]$. An essential prerequisite is, however, that the ELISAs used are evaluated for their performance characteristics. The ELISAs in the present study used inactivated influenza $A$ and $B$ viruses containing high amounts of conserved influenza type-specific nucleoand matrix proteins and were selected because of their high sensitivity and specificity. Higher antibody titres measured in the vaccinated group suggest that the assays detected also IgG antibodies induced by vaccination against seasonal and pandemic influenza. That is why the vaccination coverage was analysed, but the proportion of vaccinated children was equally low in all regions, and the vaccination rate in adults could be assumed to be low [20]. Vaccination coverage was therefore not of significance for our findings. A limitation of this study is that while the ELISAs indicate a previous infection, they provide no information about the time of infection. Antibodies to influenza virus nucleo- and matrix protein antigens fail to contribute to protection, but they indicate the presence of subtypeindependent T-cell-mediated protection [29].

In children, the overall prevalence of antibodies to influenza A was $87.6 \%$, reflecting the epidemiological dominance of seasonal and pandemic influenza $A$ over influenza B between 2007 and 2010 in Germany [30-32], and assuming that antibodies persist at least six months after infection or vaccination [23]. The seroprevalence showed an age-dependent increase until 
the age of nine to 10 years, when nearly all children had developed antibodies against influenza A virus. These data correlate well with the results published recently for children in the Netherlands [18]. The latter study was carried out with the haemagglutination inhibition test and showed that all children seven years and older had antibodies to at least one of six representative influenza $\mathrm{A}\left(\mathrm{H}_{3} \mathrm{~N}_{2}\right)$ and six representative influenza $A\left(\mathrm{H}_{1} \mathrm{~N}_{1}\right)$ virus strains selected for serological testing. Our data demonstrate that children, starting with the age of nine years, have a good basal immunity to influenza A. Thus, these children are at lower risk for potentially severe primary influenza infections and do not need a second dose of the vaccine against influenza $A$ as long as they have received the first vaccine dose. This is in agreement with findings published previously [33]. In contrast to the influenza seroprevalence in older children, nearly $40 \%$ of children under the age of four years had no influenza A virus-specific IgG antibodies. These children are immunologically naïve, and therefore have to be regarded as susceptible to potentially severe primary influenza A infection. Accordingly, Bodewes et al. [18] found the highest attack rates with primary influenza A infections, calculated on the basis of antibody prevalence, in children two and three years of age. In addition, children up to the age of six years in our study had a significantly lower influenza A seroprevalence and significantly lower antibody concentrations against influenza $A$ virus than adults. This is most likely due to the lower number of boosting influenza $A$ infections in their lifetime [2]. Adolescents at the age of 13 to 14 years had significantly higher influenza A seroprevalence, and 11 to 17 year-olds had significantly higher antibody concentrations to influenza $A$ virus than adults. These data, which correspond to results reported previously [2], may suggest that these age groups have the highest attack rates of influenza $A$ reinfections or more frequent silent boosting. However, the lower seroprevalence in adults might also be due to faster waning of immunity in older people. Among the adults, the antibody prevalence against influenza A virus was significantly higher in women than in men. These findings may be associated with the high incidence of influenza A during childhood since care of children in Germany is generally undertaken by women [34]. Since there was no information about the influenza vaccination status of our study participants, it remained unclear whether the higher prevalence of anti-influenza A antibodies may reflect a difference in vaccination status.

A different pattern was observed for the seroprevalence of influenza $B$. The overall prevalence of antibodies to influenza B in children was $47 \%$. Approximately $60-70 \%$ of all children up to the age of 12 years were serologically naïve and have to be considered susceptible to influenza B. By the age of 18 years, an influenza B seroprevalence of approximately $90 \%$ was reached. The considerably lower seroprevalence rate of $25 \%$ among 12 year-old children reported in our recent study [2], can only be interpreted in the context of the single test population from Thuringia and the different serological method used. In the present study, the group of all children and adolescents had significantly lower influenza B seroprevalences and significantly lower antibody concentrations against influenza B than adults. They seem to have had fewer infections during their lifetimes than adults [2]. It can be concluded from the current study that a natural immunity against influenza $B$ at a level comparable to influenza $A$, is only established around the age of 18 years. Since children with incomplete specific immunity may be at risk for severe courses of influenza $B[35,36]$ a seasonal vaccination against influenza $B$ could benefit all children. In Germany, there are obvious regional differences in seroprevalences of influenza B. As the present study shows, the influenza B seroprevalences of distinct German regions differ in children with a mean age of eight to 10 years between approximately $35 \%$ and $65 \%$, i.e. by as much as $30 \%$. By contrast, the overall values of influenza A seroprevalence varied by as much as approximately $16 \%$ (range: $82-98 \%$ ). This means that influenza B outbreaks, contrary to influenza A epidemics, may often be restricted to certain local regions. Multicentre studies are required to obtain representative seroprevalence data. Different rates of influenza vaccination may be of importance, but data on this are not available. Interestingly, the lowest seroprevalence of influenza B of this study was observed with $25.9 \%$ in the child population with a mean age of six years, recruited from the paediatric clinic in Erfurt, the capital of the German federal state Thuringia. Sera from children 18 years and younger in this region had been included in our previous study resulting in an overall influenza B seroprevalence of $9.6 \%$ [2]. Reasons for this variation can be differences between the serological methods used and the test populations. This means that the methods used in seroprevalence studies must be validated thoroughly.

In conclusion, this study provides representative data of influenza A and B seroprevalences in children aged up to the age of 17 years in Germany. They may have implications for the development of vaccination strategies to protect children against influenza $A$ and $B$.

\section{Acknowledgments}

This work was supported by grants of the GlaxoSmithKline GmbH \& Co. KG, Munich, Germany.

The authors are grateful to Detlef Kuehnel (German Red Cross blood donation centre Muenster, Germany) and Thomas Mueller (German Red Cross blood donation centre Springe, Germany) for providing sera of blood donors.

\section{Conflict of interest}

The co-author Ruprecht Schmidt-Ott is employed by GlaxoSmithKline Vaccines, Wavre, Belgium.

Authors' contributions 
A Sauerbrei: author of the publication, also provided analysis and interpretation of data, responsible for study design. TL: co-author of the publication, carried out the ELISAs and one part of statistical analysis. AB: co-author of the publication, carried out the second part of statistical analysis. RS-0: coauthor of the publication and responsible for study design. AK, HG, H-IH, PK, JL, A Streng, TN, JP, A Sauerbrey, HS, TT, SW and PW: co-authors, responsible for the collection of patients' samples. All authors have read and approved the final manuscript.

\section{References}

1. World Health Organization (WHO). Fact sheet No 211. Influenza (seasonal), Geneva: WHO; April 2009.]. Available from: http:// www.who.int/mediacentre/factsheets/fs211/en/index.html

2. Sauerbrei A, Schmidt-Ott R, Hoyer H, Wutzler P. Seroprevalence of influenza $A$ and $B$ in German infants and adolescents. Med Microbiol Immunol. 2009:198(2):93-101. http://dx.doi. org/10.1007/s00430-009-0108-7

3. Mossong J, Hens N, Jit M, Beutels P, Auranen K, Mikolajczyk $R$, et al. Social contacts and mixing patterns relevant to the spread of infectious diseases. PLoS Med. 2008;5(3):e74. http://dx.doi.org/10.1371/journal.pmed.0050074

4. Heikkinen T, Silvennoinen H, Peltola V, Ziegler T, Vainionpaa $\mathrm{R}$, Vuorinen $\mathrm{T}$, et al. Burden of influenza in chidren in the community. J Infect Dis. 2004;190(8):1369-73. http://dx.doi. org/10.1086/424527

5. Neuzil KM, Wright PF, Mitchel EF Jr, Griffin MR. The burden of influenza illness in children with asthma and other chronic medical conditions. J Pediatr. 2000;137(6):856-64. http:// dx.doi.org/10.1067/mpd.2000.110445

6. Streng A, Grote V, Liese JG. Severe influenza cases in paediatric intensive care units in Germany during the prepandemic seasons 2005 to 2008. BMC Infect Dis. 2011;11:233. http://dx.doi.org/10.1186/1471-2334-11-233

7. Wieching A, Benser J, Kohlhauser-Vollmuth C, Weissbrich B, Streng A, Liese JG. Clinical characteristics of pediatric hospitalizations associated with 2009 pandemic influenza A ( $\left.\mathrm{H}_{1} \mathrm{~N} 1\right)$ in Northern Bavaria, Germany. BMC Res Notes. 2012;5:304. http://dx.doi.org/10.1186/1756-0500-5-304

8. Principi N, Esposito S, Gasparini R, Marchisio P, Crovari P; FluFlu Study Group. Burden of influenza in healthy children and their households. Arch Dis Child. 2004;89(11):1002-7. http:// dx.doi.org/10.1136/adc.2003.045401

9. Antonova EN, Rycroft C, Ambrose CS, Heikkinen T, Principi N. Burden of paediatric influenza in Western Europe: a systematic review. BMC Public Health. 2012;12:968. http://dx.doi. org/10.1186/1471-2458-12-968

10. DiazGranados CA, Denis M, Plotkin S. Seasonal influenza vaccine efficacy and its determinants in children and nonelderly adults: a systematic review with meta-analyses of controlled trials. Vaccine. 2012;31(1):49-57. http://dx.doi. org/10.1016/j.vaccine.2012.10.084

11. Thors V, Smith C, Finn A. Should all children be immunized against influenza? Arch Dis Child. 2013;98(11):846-9. http:// dx.doi.org/10.1136/archdischild-2013-304681

12. Ambrose CS, Wu X, Knuf M, Wutzler P. The efficacy of intranasal live attenuated influenza vaccine in children 2 through 17 years of age: a meta-analysis of 8 randomized controlled studies. Vaccine. 2012;30(5):886-92. http://dx.doi. org/10.1016/j.vaccine.2011.11.104

13. Lee BY, Shah M. Prevention of influenza in healthy children. Expert Rev Anti Infect Ther. 2012;10(10):1139-52. http://dx.doi. org/10.1586/eri.12.106

14. Izurieta HS, Thompson WW, Kramarz P, Shay DK, Davis RL, DeStefano F, et al. Influenza and the rates of hospitalization for respiratory disease among infants and young children. N Engl J Med. 2000;342(4):232-9. http://dx.doi.org/10.1056/ NEJM200001273420402

15. Neuzil KM, Mellen BG, Wright PF, Mitchel EF Jr, Griffin MR. The effect of influenza on hospitalizations, outpatient visits, and courses of antibiotics in children. $\mathrm{N}$ Engl J Med. 2000;342(4):225-31. http://dx.doi.org/10.1056/ NEJM200001273420401

16. Weigl JA, Puppe W, Schmitt HJ. The incidence of influenzaassociated hospitalizations in children in Germany. Epidemiol Infect. 2002;129(3):525-33. http://dx.doi.org/10.1017/ So950268802007707

17. Yeolekar LR, Kulkarni PB, Chadha MS, Rao BL. Seroepidemiology of influenza in Pune, India. Indian J Med Res. 2001;114:121-6.

18. Bodewes R, de Mutsert G, van der Klis FR, Ventresca M, Wilks S, Smith DJ, et al. Prevalence of antibodies against seasonal influenza A and B viruses in children in Netherlands.
Clin Vaccine Immunol. 2011;18(3):469-76. http://dx.doi. org/10.1128/CVI.00396-10

19. von Kries R, Weiss S, Falkenhorst G, Wirth S, Kaiser P, Huppertz $\mathrm{HI}$, et al. Post-pandemic seroprevalence of pandemic influenza $A\left(\mathrm{H}_{1} \mathrm{~N}_{1}\right) 2009$ infection (swine flue) among children «18 years in Germany. PLoS One. 2011;6(9):e23955. http:// dx.doi.org/10.1371/journal.pone.0023955

20. Böhmer MM, Walter D, Falkenhorst G, Müters S, Krause G, Wichmann 0 . Barriers to pandemic influenza vaccination and uptake of seasonal influenza vaccine in the post-pandemic season in Germany. BMC Public Health. 2012;12:938. http:// dx.doi.org/10.1186/1471-2458-12-938

21. Zentrale Ethikkommission bei der Bundesärztekammer. Die (Weiter-) Verwendung von menschlichen Körpermaterialien für Zwecke der medizinischen Forschung (2003). [The (further) use of human body samples for the porpose of medical research (2003)] Berlin: Zentrale Ethikkommission bei der Bundesärztekammer, Berlin. [Accessed: 15 May 2008]. German. Available from: http://www.zentrale-ethikkommission.de/ page.asp?his=0.1.21

22. Wutzler P, Schmidt-Ott R, Hoyer H, Sauerbrei A. Seroprevalence of influenza $A$ and $B$ in pregnant women and their offspring. J Clin Virol. 2009;46(2):161-4. http://dx.doi.org/10.1016/j. jcv.2009.06.024

23. Ott U, Sauerbrei A, Lange J, Schäfler A, Walther M, Wolf G et al. Serological response to influenza A H1N1 vaccine (Pandemrix®) and seasonal influenza vaccine $2009 / 2010$ in renal transplant recipients and in hemodialysis patients. Med Microbiol Immunol. 2012;201(3):297-302. http://dx.doi.org/10.1007/ s00430-012-0231-8

24. Armitage P. Tests for linear trends in proportions and frequencies. Biometrics. 1955;11(3):375-86. http://dx.doi. org/10.2307/3001775

25. Mantel N, Haenszel W. Statistical aspects of the analysis of data from retrospective studies of disease. J Natl Cancer Inst. 1959;22(4):719-48.

26. Dunnett CW. New tables for multiple comparisons with a control. Biometrics. 1964;20(3):482-91. http://dx.doi. org $/ 10.2307 / 2528490$

27. Waalen K, Kilander A, Dudman SG Ramos-Ocao R, Hungnes 0. Age-dependent prevalence of antibodies cross-reactive to the influenza $A\left(\mathrm{H}_{3} \mathrm{~N}_{2}\right)$ variant virus in sera collected in Norway in 2011. Euro Surveill. 2012;17(19):pii=20170.

28. Tse M, Kim M, Chan CH, Ho PL, Ma SK, Guan Y, et al. Evaluation of three commercially available influenza A typespecific blocking enzyme-linked immunosorbent assays for seroepidemiological studies of influenza $A$ virus infection in pigs. Clin Vaccine Immunol. 2012;19(3):334-7. http://dx.doi. org/10.1128/CVI.05358-11

29. Cinatl J jr, Michaelis M, Doerr HW. The threat of avian influenza A $\left(\mathrm{H}_{5} \mathrm{~N}_{1}\right)$. Part IV: development of vaccines. Med Microbiol Immunol. 2007;196(4):213-25. http://dx.doi.org/10.1007/ S00430-007-0052-3

30. Robert Koch-Institut. Rückblick auf die Influenzasaison 2007/08. [Review of the influenza season 2007/08]. Epidemiol Bull. 2008;43:372-5. German. Available from: http://edoc.rki. de/documents/rki_fv/re3BNEVpkzVE/PDF/23GEplDhxT567Wl2. pdf

31. Robert Koch-Institut. Influenzasurveillance der Arbeitsgemeinschaft Influenza. Rückblick auf starke saisonale Grippewelle im Winter 2008/09, Monitoring der neuen Influenza im Sommer 2009 und Vorausschau auf die Saison 2009/10. [Influenza surveillance of the working group on influenza. Review of the strong seasonal influenza wave in winter 2008/09, monitoring the new influenza in summer 2009 and preview of the 2009/10 season]. Epidemiol Bull 2009;42:428-31. German. Available from: http://edoc.rki.de/ documents/rki_fv/rel_RorcGBwWo/PDF/26EWIC2aZmwdM_42. pdf

32. Robert Koch-Institut (RKI). Bericht zur Epidemiologie der Influenza in Deutschland Saison 2009/10. [Review of the influenza epidemiology in Germany during the season 2009/10]. Berlin: RKI; 2010. German. Available from: https:// influenza.rki.de/Saisonberichte/2009.pdf

33. Schmidt-Ott R, Schwarz T, Haase R, Sander H, Walther U, Fourneau $M$, et al. Immunogenicity and reactogenicity of a trivalent influenza split vaccine in previously unvaccinated children aged 6-9 and 10-13 years. Vaccine. 2007;26(1):32-40. http://dx.doi.org/10.1016/j.vaccine.2007.10.049

34. Kind und Beruf: Nicht alle Mütter wollen beides. [Child and work: not all mothers want both]. Wiesbaden: Statistisches Bundesamt; 2013. German. Available from: https://www. destatis.de/DE/Publikationen/STATmagazin/Bevoelkerung/201 3_02/2013_02KindUndBeruf.html

35. Troendle JF, Demmler GJ, Glezen WP, Finegold M, Romano M). Fatal influenza B virus pneumonia in pediatric patients. Pediatr Infect Dis J. 1992;11(2):117-21. http://dx.doi. org/10.1097/00006454-199202000-00011

36. Munoz FM. Influenza virus infection in infancy and early childhood. Paediat Resp Rev. 2003;4(2):99-104. http://dx.doi. org/10.1016/S1526-0542(03)00027-7 